\title{
Comparison of Direct Microscopy and Molecular Method to Detect Amoebiasis Cases from Stool Specimen and Also Identify the Entamoeba Species Involved In Infection: A Study of Nepal
}

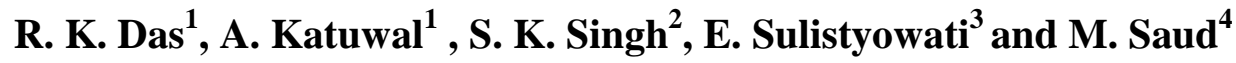 \\ ${ }^{1}$ Department of Microbiology, Tribhuvan University, Nepal. \\ ${ }^{2}$ Faculty of Economic and Business, Airlangga University, Surabaya, Indonesia. \\ ${ }^{3}$ Department of Animal Science, Faculty of Agriculture, University of Bengkulu, Indonesia \\ ${ }^{4}$ Department of Sociology, Airlangga University, Surabaya, Indonesia. \\ Correspondence address: $\underline{\text { dasrajesh5131@ gmail.com }}$
}

\begin{abstract}
Direct microscopic examination of stained or unstained wet mount preparations or fixed stained smears of clinical material can often provide the etiological diagnosis of an infectious process. A total of 266 human stool specimens from children fewer than 15 years were examined for the presence of amoebiasis by a combination of microscopic examination and molecular method. In molecular method, nested polymerase chain reaction (Nested-PCR) targeting genomic Entamoeba species was used. Stool specimens were collected from 266 participants in Southern plains of Nepal and analyzed at Kathmandu Centre for Genomics and Research Laboratory. The stool specimens were processed by wet mount method using saline as well as iodine staining and examined via microscopy for the presence of Entamoeba cysts or trophozoites. Furthermore, the stool specimens were characterized using Nested-PCR targeting genomic Entamoeba species. Based on microscopic examination, overall prevalence of Entamoeba infection was 17.6\% (47/266). The PCR results showed that $52(19.5 \%)$ out of 266 stool specimens successfully generated species-specific amplicons. Males (21.7\% in PCR) were more commonly infected compared to females (16.6\% in PCR). Comparison by age groups showed that 10-15 years age-group (26.6\% in PCR) had higher infection than age-group 5-10 years (16.6\%) years and 1-5 years $(15.2 \%)$. The infection with $E$. histolytica $(100 \% ; 52 / 266)$ was the predominant cause of amoebiasis, while infection with E. dispar and E. moshkovskii was not found. PCR is a more effective method for the identification of Entamoeba infection than microscopy. This study also suggests that older children especially male are more prone to Entamoeba infection.
\end{abstract}

Key words: Amoebiasis, wet mount method, microscopy, nested-PCR, Nepal,

\section{INTRODUCTION}

\section{Entamoeba histolytica is the} causative agent of amoebiasis and this is one of the leading parasites that cause human mortality (Haque et al., 2003, Haque et al., 2006 and WHO 1997). Each year, the parasite invades approximately 50 million people resulting in 100,000 deaths (WHO 1997). Likewise, the productivity of animals is constrained due to Entamoeba infection that can have extensive consequences, ranging from reduced animal performances to mortality (Sykes, 1994; Waller, 1999).
Although the parasite is distributed worldwide; the prevalence rate is higher in the developing countries (Stanley, 2003). Entamoeba infection spreads through fecaloral route (Blessmann et al., 2003 and Fotedar et al., 2007). Open defecation and improper disposal waste water often lead to contamination of food and water sources in developing countries and this is a serious issue contributing to human morbidity (Estevenz et al., 1983 and Gyawali et al., 2009).

Similarly, grazing management has been a serious issue behind GI infection in animals since pastures are usually not provided or not properly managed. 
Entamoeba histolytica causes gastrointestinal (GI) diseases in farm resulting in reduced productivity, weight gain as well as milk production (Jittapalapong et al., 2011).

Moreover, in some parts of the world, wastewater and human and animal excreta are used as fertilizer to increase the crop yield. This is normally practiced in China, South East Asia as well as various areas in Africa (Drechsel et al., 2011; Cross, 1985 and Timmer and Visker, 1998) with severe water scarcity. Such practices can easily contaminate food sources and spread GI infection to humans and animals.

Furthermore, lack of hygiene and poor hand washing practices among the farm workers play a major role in increasing the infection rate. Generally, E. histolytica is the common pathogen that can cause such GI diseases.

The diagnosis of an intestinal infection with $E$. histolytica is commonly made by microscopic examination of stool, in which one must recognize and differentiate the cysts or trophozoites of $E$. histolytica from those of morphologically different species. The identification of these cysts and trophozoites requires a lot of skill and patience by the microscopist. To overcome the difficulty in recognizing the pathogens and also know the species of the pathogen, molecular methods are increasingly being used for research purposes. Some molecular methods, including conventional and real-time PCR, have been developed for the detection and differentiation of Entamoeba at species level from clinical samples (Hamzah et al., 2006).
Polymerase Chain Reaction (PCR) assay allows the in vitro amplification of a specific DNA fragment in a cyclic process of denaturation, hybridization of primers, and elongation of the DNA strand using a thermostable DNA polymerase. In nested PCR, amplicons from a PCR are used as the template in a second PCR using one primer or two primers different from those used in the initial PCR and located within the sequence amplified by the first primer set. Nested PCRs are used to increase sensitivity and specificity (Messmer et al., 1997).

The study is supportive to describe the current status of amoeba infection in the endemic areas. The study has few general and specific objectives, in general it detect amoeba infection using microscopy and Polymerase Chain Reaction and also identify the Entamoeba species in the stool specimen and in particular it compares the results of PCR and microscopy for the detection of Entamoeba infection also find the Entamoeba species in stool specimen.

\section{MATERIALS AND METHODS}

This cross sectional study was carried from 15 July to 18 January 2017. For this study, stool specimens were collected from hospitals and health centers in southern plains of Nepal and analyzed in Kathmandu Centre of Genomics and Research Laboratory (KCGRL), Lalitpur, Nepal. Nepal lies in sub-tropical zone of Asia sharing its open border with India. Due to compromise in drinking water 
supply and unmanaged human settlements in southern plains, prevalence of amoebiasis is higher especially in young children who play in soil most of the time. The samples were taken from patients complaining diarrhoea from age 1 to 15 years. A total of 266 specimens were collected and processed at KCGRL. Samples from small kids were taken by the help of their care-takers. The filled and well-labeled containers were received and analyzed by microscopy on the following day; the samples were mixed with formalin and then stored under deep freeze for further processing.

\section{Microscopic Examination}

Microscopy is inexpensive and rapid technique for the identification of Entamoeba parasite. It is the gold standard tool for the diagnosis of amoebiasis cases and a method of choice for many hospitals. Saline wet mount of fresh unpreserved stool samples were examined microscopically for demonstrating Entamoeba cysts and trophozoites (Parija and Prabhakar 1995). Similarly, iodine wet mounts were prepared by adding approximately $2 \mathrm{mg}$ of stool to a drop of Lugol's iodine (diluted 1:5 with distilled water) on a glass microscope slide and placing a cover slip on the stool suspension. These wet mounts were microscopically examined initially by using a low-power $(10 \times)$ objective and then using a high-power (40x) objective of a compound light microscope. Following the extraction of genomic DNA for protozoan parasite from all the stool specimens, the specimens showing the presence of protozoan DNA were further re-checked for Entamoeba species using nested-PCR.

\section{Extraction of Entamoeba genomic DNA}

gDNA was extracted from suspected faecal specimen using mdi Stool Genomic DNA (gDNA) Miniprep Kit according to the manufacturer's instructions. Approximately, 180-220mg faecal sample was taken in a $2 \mathrm{ml}$ microcentrifuge tube and then mixed with $1.2 \mathrm{ml}$ lysis buffer MSL. Then the mixture was thoroughly homogenized and incubated at $70^{\circ} \mathrm{C}$ for 5 minutes. Followed by 15 seconds of vortexing and centrifugation at $10000 \mathrm{rpm}$ for 5 minutes to pellet stool sample, $15 \mu 1$ Proteinase k was pipetted into a new $1.5 \mathrm{ml}$ microcentrifuge tube. Now $200 \mu 1$ supernatant from centrifuged sample was mixed with Proteinase $\mathrm{k}$ in new centrifuge tube and also added $200 \mu \mathrm{l}$ Buffer SB. After short vortexing, this new mixture was incubated at $56^{\circ} \mathrm{C}$ in water bath for 15 minutes. Briefly centrifuge the mixture after incubation, add $200 \mu \mathrm{l}$ Ethanol, mix and briefly centrifuge again. Then the mixture was passed into collection tube through spin column by spinning at $10000 \mathrm{rpm}$ for 1 minute. Here, the spin column was washed in the new collection tube with $500 \mu$ l of buffer SW1 by centrifuging for 1 minute at $\geq 10000 \mathrm{rpm}$. This step was again repeated using 500ul of buffer SW2 but centrifugation was done for 3 minutes. Furthermore, the bound gDNA was eluted in the spin column placed in fresh $1.5 \mathrm{ml}$ microcentrifuge tube by adding $200 \mu 1$ of buffer SE. After incubating for 2 minutes, it was spinned $\geq 10000 \mathrm{rpm}$ for 1 
minute. Hence obtained product possessed gDNA of the processed sample. DNA thus extracted was stored was at $-20^{\circ} \mathrm{C}$ for PCR amplification.

\section{Nested PCR amplification}

Nested PCR targeting genomic DNA was used to genetically characterize E. histolytica, E. dispar and E. moshkovskii. The PCR was carried out in a $25 \mu$ l volume with the final mix containing $2.5 \mu \mathrm{l}$ PCR buffer (10x), $1.25 \mathrm{mM}$ dNTPs $(0.5 \mu \mathrm{l}), 25$ $\mathrm{mM} \mathrm{MgCl} 2(2.5 \mu \mathrm{l}), 10$ pmole of each primer $(0.15 \mu \mathrm{l}), 2.5 \mathrm{U}$ of Taq polymerase $(0.3 \mu \mathrm{l}), \quad 2.5 \mu \mathrm{l}$ of DNA template and 16.4 $\mu \mathrm{l}$ Nuclease free water.

Primary PCR for the detection of Entamoeba genus used forward primer E-1 (5'-TAA GAT GCA GAG CGA AA-3') and reverse primer E-2 (5'-GTA CAA AGG GCA GGG ACG TA-3'). For primary $\mathrm{PCR}$, the master mix was heated to $96^{\circ} \mathrm{C}$ for $2 \mathrm{~min}$, followed by 30 cycles of $92^{\circ} \mathrm{C}$ for $1 \mathrm{~min}$ (denaturing), $56^{\circ} \mathrm{C}$ for 1 minute (annealing), $72^{\circ} \mathrm{C}$ for 1 minute $30 \mathrm{~s}$ (extension) and a final extension at $72^{\circ} \mathrm{C}$ for 7 minutes.

Similarly, the products of primary PCR were used for Entamoeba speciesspecific characterization. Amplification was achieved using primer sets EH-1 (5'-AAG CAT TGT TTC TAG ATC TGA G-3') and EH-2 (5'-AAG AGG TCT AAC CGA AAT TAG-3') to detect $E$. histolytica (439 bp); ED-1(5'-TCT AAT TTC GAT TAG AAC TCT-3') and ED-2 (5'-TCC CTA CCTATT AGA CAT AGC-3') to detect E. dispar (174 bp); Mos-1 (5'-GAA ACC AAG AGT TTC ACA AC-3') and Mos-2 (5'-CAA
TAT AAG GCT TGG ATG AT-3') to detect E. moshkovskii (553 bp) (Khairnar and Parija, 2007).

For secondary PCR, the master mix was heated to $96^{\circ} \mathrm{C}$ for $2 \mathrm{~min}$, followed by 30 cycles of $92^{\circ} \mathrm{C}$ for $1 \mathrm{~min}$ (denaturing), $48^{\circ} \mathrm{C}$ for 1 minute (annealing), $72^{\circ} \mathrm{C}$ for 1 minute (extension) and a final extension at $72^{\circ} \mathrm{C}$ for 7 minutes. For both amplifications, master mix was incubated in the thermal cycler (Palm cycler). The secondary PCR amplicons were subjected to electrophoresis in $2 \%$ agarose gel stained with ethidium bromide (EtBr) at $80 \mathrm{~V}$ for 60 minute and visualized in UV illuminator.

\section{RESULTS AND DISCUSSION}

Entamoeba species was detected under microscope on the basis of morphological characteristics of the cysts or trophozoites. The average cyst size ranges from 10-20 $\mu \mathrm{m}$ in diameter. Qualitative data were estimated and presented as frequencies and percentage by using univariate analysis through SPSS statistical tool.

\section{Prevalence of Entamoeba Infection via Microscopy and PCR}

A total of 266 stool samples collected were processed through microscopy and PCR methods separately and results thus obtained varied a lot. Out of all the stool samples processed, 47 $(17.6 \%)$ samples were microscopically positive for Entamoeba cysts (Table 1). However, PCR results showed 52 (19.5\%) positive cases of Entamoeba infection 
which is higher than microscopy result (shown in Table 1).

Table 1. Entamoeba cysts analysis

\begin{tabular}{cccc}
\hline Characteristics & Total $(\mathrm{N})$ & Positive case(n) & $\%$ \\
\hline Microscopy & 266 & 47 & 17.6 \\
PCR & 266 & 52 & 19.5 \\
\hline
\end{tabular}

Ngui et al. (2012) found that 48 $(15.3 \%)$ children out of 313 children based on microscopy result suffered from amoebiasis. The parasitic infections are even higher in animals. In a study done by Huang et al. (2014) in dairy cattle in Vietnam, infection rate of protozoa alone was $81.3 \%$.

\section{Sex-wise Prevalence of Entamoeba Infection}

Microscopy result showed Entamoeba infection was more in males
$30(19.7 \%)$ compared to females 17 (14.9\%), however, it was not statistically significant (data not shown). Similarly, PCR result showed Entamoeba infection was more in males $33(21.7 \%)$ compared to females $19(16.6 \%)$, as shown in table 2 . In contrast to this result, Ngui et al (2012) found $75(17.6 \%)$ of the causative agents of illness were E.histolytica/E.dispar in microscopy in which infection was more prevalent in females $(19.1 \%)$ compared to males (15.9\%).

Table 2. Entamoeba infection by sex

\begin{tabular}{ccccccc}
\hline Sex-wise & Total (N) & \multicolumn{3}{c}{ Microscopy } & \multicolumn{2}{c}{ PCR } \\
\cline { 3 - 7 } & & $\begin{array}{c}\text { Positive } \\
\text { Case(n) }\end{array}$ & $\%$ & $95 \%$ CI & $\begin{array}{c}\text { Positive } \\
\text { Case(n) }\end{array}$ & $\%$ \\
\hline Male & 152 & 30 & 19.7 & 33 & 21.7 \\
Female & 114 & 17 & 14.9 & 19 & 16.6 \\
Total & 266 & 47 & 17.6 & 52 & 19.5 \\
\hline
\end{tabular}

\section{Age-wise Prevalence of Entamoeba Infection}

Age-wise study of Entamoeba infection detected via microscopy and PCR methods showed following results as shown in Table 3.

Table 3. Entamoeba infection by Age-wise

\begin{tabular}{cccccc}
\hline Age-group (year) & Total(N) & \multicolumn{4}{c}{ PCR } \\
\cline { 3 - 6 } & & $\begin{array}{c}\text { Positive } \\
\text { Case }(\mathrm{n})\end{array}$ & $\%$ & $\begin{array}{c}\text { Positive } \\
\text { Case(n) }\end{array}$ & $\%$ \\
\hline $1-5$ & 59 & 8 & $13.6 \%$ & 9 & $15.2 \%$ \\
$5-10$ & 132 & 21 & $15.9 \%$ & 22 & $16.6 \%$ \\
$10-15$ & 75 & 18 & $24 \%$ & 20 & $26.6 \%$ \\
\hline Total & 266 & 47 & $17.6 \%$ & 52 & $19.5 \%$ \\
\hline
\end{tabular}

This table states that out of total samples processed through microscopy and
PCR, highest prevalence was found in agegroup 10-15 years i.e. $18(24 \%)$ and 20 
(26.6\%) respectively. But the age-group 1-5 years had least prevalence of $8(13.6 \%)$ and $9(15.2 \%)$ in microscopy and PCR respectively.

The PCR results were positive for only one species of Entamoeba i.e. E. histolytica. Other species i.e. E. dispar and E. moshkovskii were not detected in any of the samples. Thus the chances of mixed infection were also ignored.

Although, the microscopic observation showed 47 positive cases of Entamoeba infection out of 266 total stool specimens, it was not considered overall prevalence in this study population. The present study found an overall prevalence of Entamoeba infection as determined by PCR as $17.6 \%$ (52/266). Thus the molecular method has been found more effective in contrast to microscopy. This study also suggests that relying only on microscopy cannot diagnose accurate cases of amoebiasis.

A study conducted on children in Kathmandu, Nepal reported 10\% (50/500) of the causative agents of diarrhoea were $E$. histolytica (Pokharel et al., 2007) which is consistent with this study. A recent study in India also has more or less similar results of 19\% positive Entamoeba infection based on microscopic examination (Nath et al., 2015). In a study conducted by Tuzemen and Dogan (2015), among 354 stool samples, $84 \quad(23.7 \%)$ were found E.histolytica/E.dispar positive by direct microscopy and 9 (2.5\%) by PCR methods. Although there is some similarity with the microscopy result with the current study but PCR result has a big difference.

Table 4. Molecular technique of detecting other Entamoeba species

\begin{tabular}{ccccccc}
\hline $\begin{array}{c}\text { Age group } \\
\text { (year) }\end{array}$ & Total (N) & $\begin{array}{c}\text { PCR } \\
\text { Positive } \\
\text { case }(\mathrm{n})\end{array}$ & E. histolytica & E. dispar & E. moshkovskii & $\%$ \\
\hline $1-5$ & 62 & 9 & 9 & 0 & 0 & $15.2 \%$ \\
$5-10$ & 137 & 22 & 22 & 0 & 0 & $16.6 \%$ \\
$10-15$ & 81 & 20 & 20 & 0 & 0 & $26.6 \%$ \\
Total & 280 & 52 & 52 & 0 & 0 & $19.5 \%$ \\
\hline
\end{tabular}

This molecular technique showed that E. histolytica (100\%) was the only agent among Entamoeba species causing illness in the study population. E. dispar/ E. moshkovskii were not detected in any of the samples taken from symptomatic cases (shown in Table 4). From this finding, it can also be predicted that the causative agents of diarrhoea were either $E$. histolytica or bacteria or virus or some other agents but not E. dispar/ $E$. moshkovskii. Since, molecular studies targeting the Entamoeba species have not yet been done in Nepal; it is very difficult to understand the prevalence due to $E$. disparl E. moshkovskii in Nepal. E. disparl E. moshkovskii although are nonpathogenic, they have already been identified in neighboring countries (India and Bangladesh) (Khairnarnar, Parija 2007; Ali et al., 2003) and thus it can be 
speculated that they may exist in Nepal even though not identified in this study.

Although human cases infected with E. moshkovskii have been reported sporadically from different parts of the world including India (Khairnar and Parija 2007) Bangladesh (Ali et al., 2003) and Australia (Fotedar et al., 2007), they have been attributed to asymptomatic infection most frequently. The global prevalence of E. dispar/E. histolytica is quite uncommon with this study but it cannot be ignored that a single study with limited number of subject's i.e. only children may not be sufficient to assess the overall prevalence of Entamoeba species over certain geographic location. Therefore, future investigation which includes the clinical impact of $E$. moshkovskii and other Entamoeba species is imperative for a better understanding of a true pathogenic potential of E. moshkovskii.

Sex-wise study shows higher prevalence in males in comparison to females both in microscopy and PCR. This could be attributed to the fact that male members have freedom to participate in outside activities in southern plains of Nepal while the female children have family restriction and need permission of their parents to move out of their house. This situation play a bigger role in transmitting the amoebiasis in male children than female children as one would eat contaminated food or drink water while they are outside their houses. Furthermore, open defecation and eating without washing the hands has further impact of being infected.
Age-wise study shows increasing prevalence of amoebiasis with increasing age of children. The possible reason for this may be more or less the same as sex-wise prevalence. As a child grows older, he can go outside their house to play with their friends, swim in the nearby rivers or lakes which are already polluted by open defaecation. Moreover, there is no provision of clean drinking water in most of the schools of Nepal as well. Contaminated water or food may contain Entamoeba cysts and can easily transmit the infection (Chakraborty, 2001).

The participants of this study were from the southern plains of Nepal where there is no easy access to clean drinking water and living condition is poor. Given the faeco-oral route of amoebiasis, habits related to eating, defaecation, personal hygiene, cleanliness and level of education may have an impact on the prevalence rates (Ngui et. al 2012). Because of such unhygienic practices, the chances of parasitic infections have persisted (Sherchand SB 1997and Maharjan et al., 2007). The majority of the people in Nepal still live in the rural areas where literacy rate is quite lower. Unavailability of medical facilities and social awareness in such regions may contribute to high prevalence of Entamoeba infection.

\section{CONCLUSION}

In conclusion, PCR is a more effective method for the identification of Entamoeba infection than microscopy. In the southern plains of Nepal, E. histolytica 
is the major cause of amoebiasis and male children are more prone to Entamoeba infection. Besides, older children are more vulnerable to amoebiasis than young children.

\section{REFERENCES}

Ali, I.K.M., M.B. Hossain, S. Roy, P. Ayeh-Kumi, J.W.A. Petri, R. Haque, and C.G. Clark. 2003. Entamoeba moshkovskii infections in children, Bangladesh. Emerge Infect Disemerging. 9:580-584.

Braga, L., M.L. Gomes, M.W. Silva, C. Paiva, A. Sales, B.J. Mann. 2001. Entamoeba histolytica and Entamoeba dispar infections as detected by monoclonal antibody in an urban slum in Fortaleza, Northeastern Brazil Rev Soc Bras Med Trop.

Chakraborty, P. K. 2001. A text book of Microbiology, 1st edition. New Central Book agency (P) Ltd, Calcutta.

Cross, P. 1985. Health Aspects of Night soil and Sludge Use in Agriculture and Aquaculture-Part I: Existing Practices and Beliefs in the Utilization of Human Excreta. International Reference Center for Waste Disposal (No 04/85), Dubendorf, Switzerland.

Drechsel, P. C. A. Scott, L. Raschid-Sally, A.B. $\quad 2010$. Wastewater irrigation and health -
Assessing and mitigating risk in lowincome countries. Sterling, VA, London: Earthscan.

Estevez, E. G., J.A. Levine, J. Warren. 1983. Intestinal parasites in a remote village in Nepal J Clin Microbiol. 17:160-1

Fotedar, R. D. Stark, N. Beebe, D. Marriott, J. Ellis, and J. Harkness. 2007. PCR detection of Entamoeba histolytica, Entamoeba dispar, and Entamoeba moshkovskii in stool samples from Sydney, Australia. J Clin Microbiol 45:1035-1037.

Gyawali, N., R. Amatya. 2009. Nepal PH Intestinal parasitosis in school going children of Dharan Municipality, Nepal Trop Gastroenterol. 30 (3):1457.

Hamzah, Z., S. Petmitr, M. Mungthin, S. Leelayoova, P. ChavalitshewinkoonPetmitr. 2006. Differential detection of Entamoeba histolytica, Entamoeba dispar, and Entamoeba moshkovskii by a single-round PCR assay J Clin Microbiol. 44:3196-3200.

Haque, R., C. D. Huston, M. Hughes, E. Houpt, and W. A. Petri- Jr. 2003. Current concepts: amoebiasis N Engl J Med 348:1565-1573.

Haque, R., and W. A. Petri- Jr. 2006. Diagnosis of amoebiasis in Bangladesh. Arch Med Res 37:273276 
Jittapalapong, S., A. Sangwaranond B. Nimsuphan, T. Inpankaew, C. Phasufk, N. Pinyopanuwat, W. Chimnoi, C. Kengradomkij, P. Arunwipat, T. Anakewith. 2011. Prevalence of Gastro-Intestinal Parasites of Dairy Cows in Thailand. Kasetsart Journal - Natural Science. 45. 40-45.

Khairnar, K., S.C. Parija. 2007. A novel nested multiplex polymerase chain reaction (PCR) assay for differential detection of Entameoba histolytica, $E$ moshkovskii and $E$ dispar DNA in stool samples BMC Microbiol. 7:47.

Huang, C.C., L.C. Wang, C.H. Pan, C.H.Yang, C.H. Lai. 2014. Investigation of gastrointestinal parasites of dairy cattle around Taiwan; Journal of Microbiology, Immunology and Infection, 47(1) :7074.

Maharjan, A., J.B. Sherchand, B. Pradhan, A. Paudyal, A.R. Panta. 2007. Rotavirus infection among Diarrheal Children Attending Kanti Children Hospital, Kathmandu, Nepal. Journal of Nepal Health Research Council. 4 : 34-40.

Messmer, T.O., S.K. Skelton, J.F. Moroney, H. Daudharty, B.S. Fields. 2003. Application of a Nested, Multiplex PCR to Psittacosis Outbreaks. Microbiol. 41:5041-5.

Nath, J., S.K. Ghosh, B. Singha, J. Paul. 2015. Molecular Epidemiology of Amoebiasis: A Cross-Sectional Study among North East Indian Population.
Haque R, ed. PLoS Neglected Tropical Diseases. 9(12):e0004225.doi:10.1371/journal.p ntd.0004225.

Ngui, R., L. Angal, S. H. Fakhrurrazi, Y. L. Ai Lian, $\quad$ L. Y. Ling, J. Ibrahim and R. Mahmud. 2012. Differentiating Entamoeba histolytica, Entamoeba dispar and Entamoeba moshkovskii using nested polymerase chain reaction (PCR) in rural communities in Malaysia, Parasit Vectors. 5: 187.

Parija, S. C., P. K. Prabhakar. 1995. Evaluation of lacto-phenol cotton blue for wet mount preparation of feces J Clin Microbiol. 33:10191021.

Pokharel, M., J.B. Sherchand, H.C. Upreti, A. Katuwal, and P. Gauchan. 2007. A Perspective Study on the Etiology of Diarrhea in ChildrenLess than 12 Years of age attending Kanti Children's Hospital; J. Nepal Paediatr. Soc. 29(1) : 10-16.

Sherchand, J. B. 1997. Intestinal parasitic infection in Southern Nepal. Journal of Institute of Medicine.

Stanley, S. L. Jr. 2003. Amoebiasis Lancet. 361:1025-1034.

Stensvold, C. R., and H.V. Nielsen. 2012. Comparison of Microscopy and PCR for Detection of Intestinal Parasites in Danish Patients Supports an Incentive for Molecular Screening J. Clin. Microbiol. February. 50 (2) : 540541. 
Sykes, A. R. 1994. Parasitism and production in farm animals. Anim. Prod. 59: 155-172.

Timmer, L., C. Visker. 1998. Possibilities and Impossibilities of the use of human excreta as fertiliser in agriculture in sub-Saharan Africa. Royal Tropical Institute and University of Amsterdam, The Netherlands.
Waller, P.J. 1999. International approaches to the concept of integrated control of nematode parasites of livestock. Int. J. Parasitol. 29: 155-164.

WHO. $1997 . \quad$ World Health Organization/Pan American Health Organization/UNESCO report of a consultation of experts on amoebiasis. Wkly Epidemiol Rec WHO. 72: 9799. 